\title{
Get Involved: Kinga Unocic, TMS 2012 Session Organizer
}

\author{
Kelly Zappas
}

"Get Involved" is a recurring End Notes feature that spotlights the work of TMS volunteers and shows the wide range of volunteer activities available through TMS. This month features Kinga Unocic, a research staff member at Oak Ridge National Laboratory. As a member of the TMS Young Leaders Committee, Unocic is helping to organize a brand new event for the TMS 2012 Annual Meeting \& Exhibition, which will be held in Orlando, Florida, in March.

Q. You are helping to organize a new event, called the Meet the Candidate Employment Poster Session, for the TMS 2012 Annual Meeting. Could you briefly describe this event for our readers?

A. The Meet the Candidate Employment Poster Session is a new TMS event designed to create networking opportunities for young professionals that will allow them to connect with potential employers for post-doctoral, full-time, or faculty positions. Candidates will present a poster to potential employers. We hope to bring a number of employers from various universities, industries, and national labs.

The event will be held on Sunday afternoon, March 11, 2012. We are planning to have an information board, which will indicate the name of the candidate, the title of their poster, and the location and times for their oral presentations, if applicable, during the week of the conference. Moreover, there will be a main desk that will provide additional information for employers (for example, resumes of the candidates), and for candidates (for example, advertising brochures of the employers).

Q. Where did you get the idea for this new session?

A. Actually, the idea for the event was proposed by Michele Manuel, a young faculty member at the University of Florida, at one of our Young Leaders Committee meetings. The event was inspired by the success of the American Institute of Chemical Engineers' (AIChe) Meet the Faculty Candidate Poster Session held at their national conference.

Q. What role did the Young Leaders Committee play in making this idea a reality?

A. The Young Leaders Committee plays a major role in organizing this event, with help from Bryn Simpson, TMS member services specialist, from the initial allocation of support funds through program planning and determining the location and time of the event.

Q. Why do you think the session will be a valuable event for TMS meeting attendees?

A. A large number of students and early career professionals regularly attend the TMS Annual Meeting to present research and network with potential employers. Additionally, TMS 2012 is held before big spring graduation events. It makes logical sense to create this forum, where candidates can showcase the research that will leverage their future.

Q. Who can participate in this event?

A. Actually, anybody who is looking for career opportunities. The participants need to submit an abstract by December 15, 2011 via ProgramMaster (www.programmaster. org/am2012) that will be reviewed by the organizing committee. After the abstract is selected, candidates will be able to present a poster about their research or future interest at the TMS
2012 Annual Meeting. We would like the poster to be a showcase of the individual's talent to future employers in their own creative way. This event is being organized for the first time, and therefore we are taking about 52 posters.

Q. What advice would you give to other TMS members who want to propose new events or programming at a TMS meeting?

A. For young professionals, a good way to get started would be to attend and be involved in the Young Leaders Committee meeting, which is always held at annual TMS and MS\&T meetings. If you do not have the opportunity to do so, please visit our website, where you'll find the contact information of a Young Leaders Committee member. Send us an e-mail and we'll be happy to provide advice and suggestions. It's that simple. For other members, attending a committee meeting in your technical interest area might be a good starting point.

Q. Why do you volunteer with TMS and the Young Leaders Committee?

A. As with all volunteers, we seek to make a difference. Through continued volunteering activities, you learn more about creating a successful forum. Additionally, I am strongly encouraged by senior staff scientists at Oak Ridge National Laboratory to be involved in TMS and the Young Leader Committee.

Kelly Zappas is a contributing writer for TMS. 